\title{
The role of coagulation/fibrinolysis during Streptococcus pyogenes infection
}

\author{
Torsten G. Loof, Christin Deicke and Eva Medina* \\ Infection Immunology Research Group, Helmholtz Centre for Infection Research, Braunschweig, Germany
}

\section{Edited by:}

Emmanuelle Charpentier, Umeå

University, Sweden

\section{Reviewed by:}

Glen C. Ulett, Griffith University, Australia

Eduard Torrents, Institute for

Bioengineering of Catalonia, Spain

*Correspondence:

Eva Medina, Infection Immunology

Research Group, Helmholtz Centre for Infection Research,

Inhoffenstrasse 7,

38124 Braunschweig, Germany

e-mail: eva.medina@

helmholtz-hzi.de
The hemostatic system comprises platelet aggregation, coagulation and fibrinolysis and is a host defense mechanism that protects the integrity of the vascular system after tissue injury. During bacterial infections, the coagulation system cooperates with the inflammatory system to eliminate the invading pathogens. However, pathogenic bacteria have frequently evolved mechanisms to exploit the hemostatic system components for their own benefit. Streptococcus pyogenes, also known as Group A Streptococcus, provides a remarkable example of the extraordinary capacity of pathogens to exploit the host hemostatic system to support microbial survival and dissemination. The coagulation cascade comprises the contact system (also known as the intrinsic pathway) and the tissue factor pathway (also known as the extrinsic pathway), both leading to fibrin formation. During the early phase of $S$. pyogenes infection, the activation of the contact system eventually leads to bacterial entrapment within a fibrin clot, where S. pyogenes is immobilized and killed. However, entrapped S. pyogenes can circumvent the antimicrobial effect of the clot by sequestering host plasminogen on the bacterial cell surface that, after conversion into its active proteolytic form, plasmin, degrades the fibrin network and facilitates the liberation of $S$. pyogenes from the clot. Furthermore, the surface-localized fibrinolytic activity also cleaves a variety of extracellular matrix proteins, thereby enabling $S$. pyogenes to migrate across barriers and disseminate within the host. This review summarizes the knowledge gained during the last two decades on the role of coagulation/fibrinolysis in host defense against $S$. pyogenes as well as the strategies developed by this pathogen to evade and exploit these host mechanisms for its own benefit.

Keywords: Streptococcus pyogenes, coagulation system, contact system, fibrinogen, fibrinolysis, plasminogen

\section{ACTIVATION OF THE CONTACT SYSTEM BY S. PYOGENES}

The intrinsic pathway of coagulation, also known as kallikrein/kinin system or contact system consists of four components; the serine proteinases factor XI (FXI) and factor XII (FXII), the plasma kallikrein (PK), and the non-enzymatic cofactor, high molecular weight kininogen (HK) (Colman and Schmaier, 1997) (Figure 1). Under physiological conditions, these factors circulate as zymogens in the bloodstream or are assembled on the surface of various cell types including endothelial cells, platelets, and polymorphonuclear neutrophils (Colman and Schmaier, 1997). Despite intensive research, the function of the contact system remains enigmatic. A major role of the contact system in the initiation of the coagulation pathway has been questioned based on the absence of bleeding disorders in individuals with hereditary deficiency on FXII (Zeerleder et al., 1999). This is further supported by the normal bleeding phenotype exhibited by FXII-deficient mice (Renné et al., 2005). Interestingly, FXII deficiency in mice was associated with a profound defect in the formation and stabilization of platelet-rich thrombi (Renné et al., 2005). Thus, it was proposed that activation of the extrinsic pathway of coagulation in response to vascular injury would initiate the thrombus formation, thereby providing a surface for assembly of the contact system that would further support thrombus development and stabilization (Renné et al., 2005, 2012). A role of the contact system in immunity and inflammation has also been suggested (Frick et al., 2007; Renné, 2012).

Activation of the contact system is triggered upon binding of FXII to negatively charged surfaces, such as dextran sulfate or kaolin as well as to several biological activators including DNA, RNA, and collagen (reviewed by Maas et al., 2011). Contact factors can also become activated after binding to bacterial surfaces (reviewed by Nickel and Renné, 2012). Thus, contact factors have been reported to bind to the surface of gram-negative (Herwald et al., 1998; Holm et al., 2011; Murphy et al., 2011; RapalaKozik et al., 2011) as well as gram-positive (Ben Nasr et al., $1996,1997)$ bacteria. In the particular case of S. pyogenes, FXII undergoes autoactivation (FXIIa) after binding to the bacterial surface. Subsequently, FXIIa activates PK and FXI, also anchored to the bacterial surface via $\mathrm{HK}$ bound to the streptococcal $\mathrm{M}$ protein (Ben Nasr et al., 1995) (Figure 2). Activation of FXI triggers the intrinsic pathway of coagulation leading to the formation of thrombin and of a fibrin clot (Figure 2). On the other hand, activation of PK by FXIIa induces the cleavage of HK 


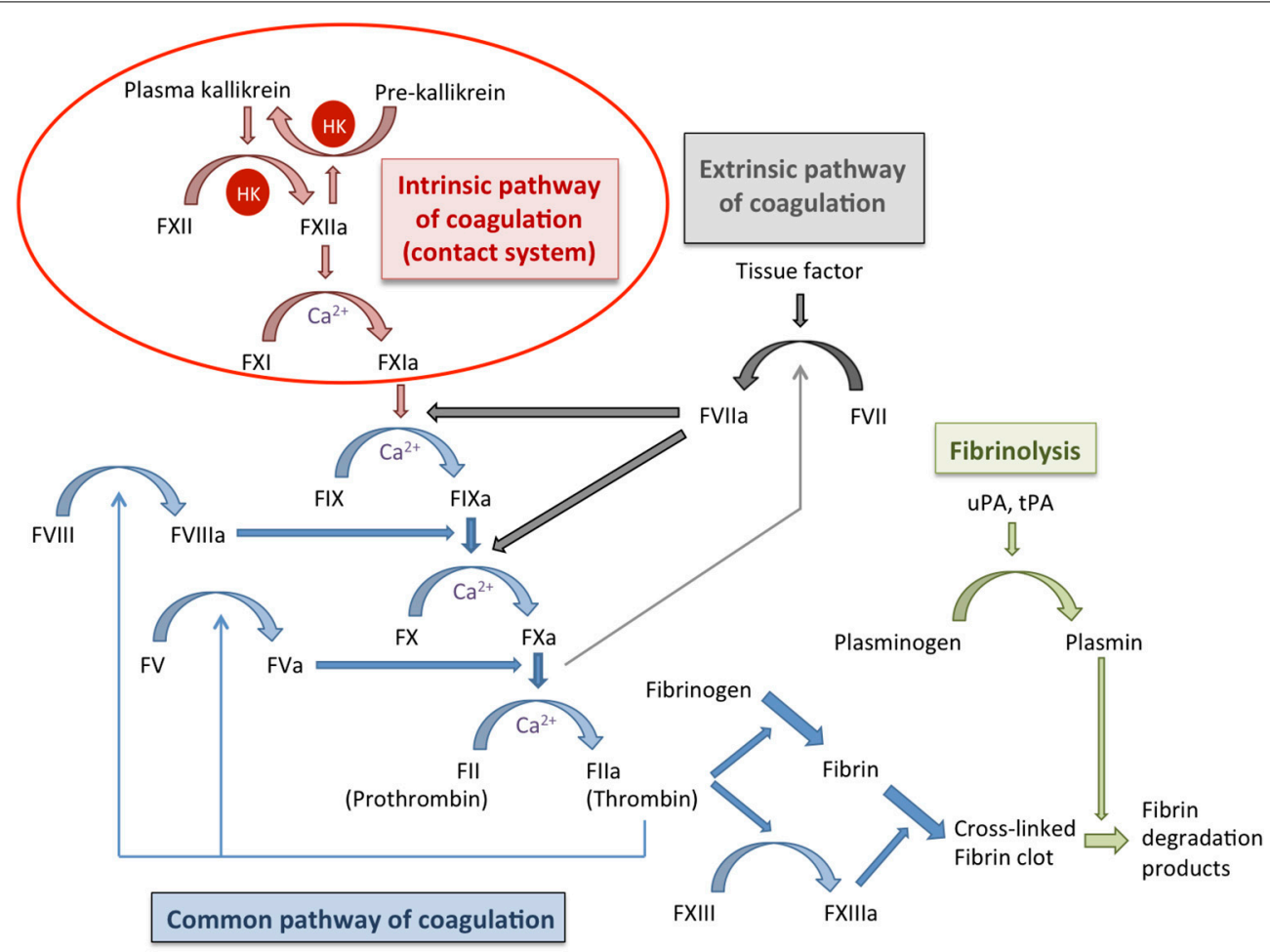

FIGURE 1 | Schematic representation of the coagulation cascade and the fibrinolytic system. The coagulation cascade (blue arrows) can be activated during hemostasis via the intrinsic pathway (contact system; red arrows) or the extrinsic pathway (gray arrows) that ultimately converge on the common pathway of coagulation. Both pathways lead to the activation of factor $X$ and subsequently of thrombin, which is required for the conversion of fibrinogen into fibrin and for activation of factor XIII. The fibrin clot is cross-linked and stabilized by factor XIII. Fibrinolysis (green arrows) is activated the same time that the coagulation system but operates more slowly and is important for the regulation of hemostasis. During fibrinolysis, plasminogen is converted into plasmin that degrades the fibrin network. Coagulation factors are indicated with "F" followed by a roman numeral, an additional "a" denotes the activated form; $H K$, high molecular weight kininogen; uPA, urokinase plasminogen activator; tPA, tissue plasminogen activator.

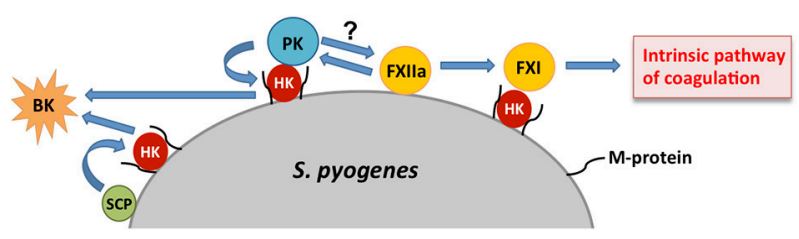

FIGURE 2 | Schematic representation of contact activation on the surface of $\boldsymbol{S}$. pyogenes. Assembly of coagulation factors on the surface of $S$. pyogenes leads to an autoactivation of factor XII (FXIla) that, in turn, activates factor XI (FXI) and plasma kallikrein (PK), both anchored to the bacterial surface via high molecular weight kininogen (HK) bound to the streptococcal M protein. Activated FXI triggers the intrinsic pathway of coagulation while PK induces the cleavage of $\mathrm{HK}$ resulting in the generation of bradykinin (BK). HK immobilized on the bacterial surface can be also cleaved by the streptococcal cysteine proteinase (SCP).

and the generation of the vasoactive and proinflammatory peptide bradykinin (BK) (Figure 2). Furthermore, the streptococcal cysteine proteinase SCP has been also identified as one of the bacterial factors involved in the cleavage of $\mathrm{HK}$ without requiring previous activation of PK (Herwald et al., 1996) (Figure 2). Based on these observations, it was proposed that the recruitment of high amounts of $\mathrm{HK}$ by the $\mathrm{M}$ protein on the surface of $S$. pyogenes could lead to a local burst of kinins by the action of SCP. This would result in increased vascular permeability leading to exudation of high amounts of plasma proteins and nutrients into the site of infection (Herwald et al., 1996). Extravasation of massive fluid from the intravascular compartment out into the tissues can induce a drop in blood pressure that can contribute to the development of sepsis and septic shock, which are the most severe clinical outcomes of $S$. pyogenes infections (Henningham et al., 2012). Further evidence supporting an activation of the contact system during invasive streptococcal infection was provided by the prolonged activated partial thromboplastin time (aPTT) observed in mice experimentally infected with $S$. pyogenes (Sriskandan et al., 2000). Prolonged aPTTs have also been detected in patients with septic shock (Smith-Erichsen et al., 1982) and extensive pulmonary hemorrhage has been observed in post-mortem examination of lungs isolated from patients that succumbed after fulminant S. pyogenes infection (Ooe et al., 1999).

S. pyogenes M1 protein as well as other bacterial virulence factors have been reported to stimulate the production of procoagulant microversicles, which are small particles released from the cell membrane of activated or apoptotic cells (Piccin et al., 2007) and from peripheral blood mononuclear cells (Oehmcke et al., 2012). S. pyogenes has been shown to induce apoptosis 
in several host cell types such as neutrophils, keratinocytes and epithelial cells through different virulence factors and this has been suggested to play a role in the infectious process (for review see Ulett and Adderson, 2006). Activation of the contact system on these microvesicles was shown to contribute to clot stabilization and stimulation of inflammatory responses by the generation of BK (Oehmcke et al., 2012). Pro-coagulant monocyte-derived microvesicles were also found in plasma from septic patients (Oehmcke et al., 2012).

In summary, experimental animal studies and clinical data indicate a link between activation of the contact system and invasive $S$. pyogenes infections. Therefore, interfering with the activation of the contact system has been considered as therapeutic intervention to improve the outcome of severe invasive S. pyogenes infection. As proof of principle, treatment with a peptide (HKH20) derived from the region of human HK involved in the binding to negative charged surfaces (Hasan et al., 1995), was shown to block the assembly and activation of the contact system and to prevent lung bleedings and early mortality of $S$. pyogenes-infected mice when administered in combination with clindamycin (Oehmcke et al., 2009a).

\section{THE ROLE OF THE COAGULATION SYSTEM IN INNATE HOST DEFENSE AGAINST S. PYOGENES}

It has been proposed that the vertebrate coagulation system is evolutionarily a by-product of the innate immune system, with the blood clotting factors having diverged from the complement system (Krem and Di Cera, 2002). In this regard, there is a growing body of evidence suggesting the contribution of the coagulation system to host defense against invading pathogens. The role of the coagulation system in early innate immune defenses is most prominent in $S$. pyogenes infections. For example, the D3 domain of $\mathrm{HK}$, has been reported to exert direct antimicrobial activity against $S$. pyogenes (Frick et al., 2006). HK is organized into six structural domains: domains 1-3 (D1-D3) are related to cystatin, D4 contains the BK peptide, D5 mediates binding to negatively charged surfaces, and the carboxyl-terminal D6 contains a zymogen binding sequence for FXI and prekallikrein which, with D5, accounts for its cofactor activity (Colman and Schmaier, 1997). Although intact HK does not have anti-bacterial effect, the D3 fragments released after enzymatic cleavage of HK by for example neutrophils elastase (Vogel et al., 1988), possess strong bactericidal activity (Frick et al., 2006). Thus, it was proposed that, after assembly and activation of the contact system on bacterial surfaces, HK can be cleaved by elastase released by activated neutrophils, resulting in the simultaneous release of antibacterial D3 fragments and BK that will further promote inflammation and plasma leakage (Frick et al., 2006). Other components of the contact system such as the domain D5 of HK have been also reported to exert antimicrobial effect (Nordahl et al., 2005).

Contact activation leads to the induction of the entire coagulation cascade and there is evidence that entrapment of microorganisms after clot formation may hamper their dissemination from the local site of infection. This mechanism appears to be highly conserved during evolution from invertebrates to humans (Rotstein, 1992; Sun et al., 2004; Matsuda et al., 2007; Loof et al., 2011a) and it has been designated as "immunothrombosis" by Engelmann and Massberg (2013). The ultimate goal of the coagulation pathway is to produce thrombin, which is generated from its inactive precursor prothrombin by the prothrombinase complex formed by FXa and its co-factor FVa. The main functions of thrombin are the conversion of fibrinogen to fibrin as well as the activation of coagulation FXIII. Fibrin strands are then cross-linked by activated FXIII (FXIIIa) to form a stable blood clot (Figure 1). During the process of thrombin generation in blood, part of the early-generated thrombin feeds back on the cascade system to activate FV and FVIII (Figure 1), thus promoting further thrombin generation (Brummel et al., 2002). Thrombin generation takes place on the surface of activated platelets that form the primary hemostatic plug (Brass, 2003). The relevance of thrombin generation in antimicrobial host defense against $S$. pyogenes was examined by Sun and co-workers using mice with deficiency of FV in either the plasma or the platelet compartment (Sun et al., 2009). They reported that reduction of FV in either pool resulted in increased mortality of mice after subcutaneous inoculation of $S$. pyogenes, thus supporting a role of thrombin generation in host defense against this pathogen (Sun et al., 2009). The authors hypothesized that local fibrin deposition mediated by both the platelet and plasma FV pools could reduce the survival and dissemination of $S$. pyogenes by limiting vascular invasion and hematogenous spread (Sun et al., 2009). The capacity of the fibrin clot to immobilize and kill S. pyogenes was first demonstrated by Shannon et al. (2010). They also demonstrated that histidinerich glycoprotein (HRP), an abundant plasma protein, played a critical role in this defense mechanism (Shannon et al., 2010). Thus, clots formed in HRG-deficient plasma were less effective than those formed in normal plasma at entrapping and killing S. pyogenes (Shannon et al., 2010). Furthermore, HRG-deficient mice exhibited increased susceptibility to $S$. pyogenes infection than wild-type mice, a phenotype that was reverted after supplementing the HRG-deficient mice with purified HRG (Shannon et al., 2010). FXIII was also shown to be an important factor for the entrapment of different bacterial pathogens within clots since clots generated in plasma from FXIII-deficient individuals lost the capacity to immobilize bacteria (Wang et al., 2010). Therefore, FXIII-mediated entrapment of pathogens within a fibrin clot seems to be a general immune defense mechanism against bacterial pathogens (Wang et al., 2010). It has also been reported that FXIII mediates cross-linking of bacterial surface structures, such as the M1 protein of $S$. pyogenes, to fibrin fibers within the clot, where the microorganisms are subsequently killed by the induction of plasma-derived antimicrobial activity (Loof et al., 2011b). The electron microscopy photographs depicted in Figure 3 show the FXIII-mediated entrapment of S. pyogenes bacteria of strain AP1 (serotype M1) in a fibrin clot. A large amount of bacteria were enwoven within the fibrin network when the clot was generated in normal human plasma (Figure 3A) whereas only a few bacteria are found loosely associated with the clot when FXIII-deficient plasma was used (Figure 3B). It was also reported that mice deficient in FXIII exhibited higher levels of local inflammation than wild-type mice after subcutaneous inoculation with S. pyogenes (Loof et al., 2011b). Furthermore, streptococci were found confined within the fibrin 

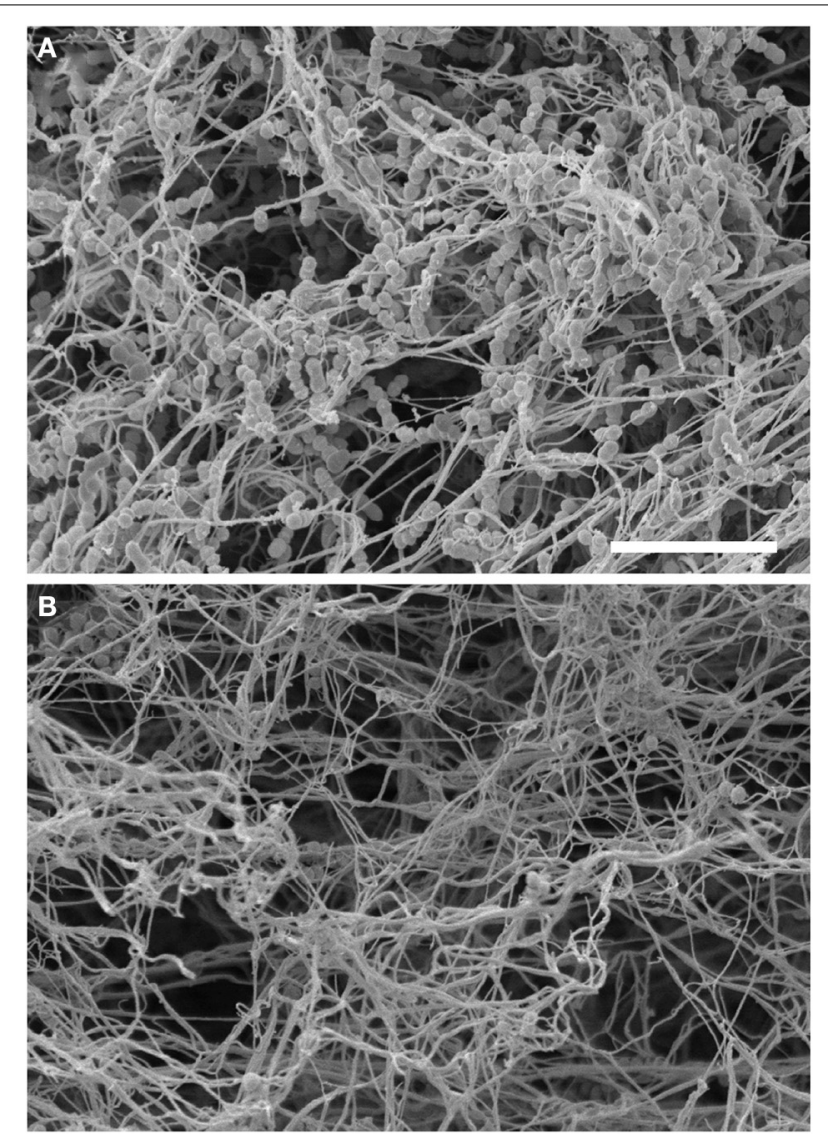

FIGURE 3 | Entrapment of $\boldsymbol{S}$. pyogenes within a fibrin clot is mediated by Factor XIII. Scanning electron micrograph of $S$. pyogenes bacteria of strain AP1 (M1 serotype) within a clot generated in normal human plasma (A) or in Factor XIII-deficient human plasma (B). The scale bar represents $10 \mu \mathrm{m}$.

meshwork in skin biopsies from infected wild-type mice, but they were spread throughout the site of infection in infected FXIII-deficient mice (Loof et al., 2011b). A similar immobilization of bacteria within fibrin networks was also observed in skin biopsies obtained from patients with severe $S$. pyogenes infections (Loof et al., 2011b). These observations underscore the relevance of FXIII in the early control of $S$. pyogenes infection.

\section{THE ROLE OF FIBRINOGEN IN INNATE HOST DEFENSE AGAINST S. PYOGENES}

Fibrinogen is a plasma glycoprotein synthesized in the liver that is essential for blood coagulation. In order to form a clot, soluble fibrinogen must be converted into insoluble fibrin polymer by thrombin (Blombäck et al., 1978). Fibrinogen has been suggested to play an important role in host defense against S. pyogenes by limiting both bacterial hematogenous dissemination and by promoting inflammation leading to bacterial clearance (Sun et al., 2004, 2009). Thus, it was reported that reduction of fibrinogen levels after injection of snake venom enhanced the mortality of $S$. pyogenes-infected mice (Sun et al.,
2004). Furthermore, mice deficient in the production of fibrinogen $\left(\mathrm{Fga}^{-}--\right)$were also highly susceptible to $S$. pyogenes (Sun et al., 2009).

The important role played by fibrinogen for confining and neutralizing $S$. pyogenes during the early infection was further demonstrated by Påhlman et al. (2013). This group showed that the peptide fragment GHR28 released from the $\beta$-chain of fibrinogen after activation with thrombin exerted antimicrobial activity against $S$. pyogenes organisms entrapped within a fibrin clot (Påhlman et al., 2013). Nevertheless, binding of plasminogen to the bacterial surface was a pre-requisite for effective bacterial killing (Påhlman et al., 2013). Kantor and Cole described for the first time the capacity of a $S$. pyogenes factor, which they named FPF (fibrinogen precipitating factor), to precipitate human and bovine fibrinogen (Kantor and Cole, 1959). In further experiments, Kantor confirmed the identity of FPF and M protein (Kantor, 1965). The M protein is the major virulence determinant of $S$. pyogenes by virtue of its ability to promote the survival of the bacterium in human blood (Fischetti, 1989; Oehmcke et al., 2010). M protein is exposed on the surface of $S$. pyogenes but it can also be released after proteolytic cleavage by cysteine proteinases also secreted by S. pyogenes (Berge and Björck, 1995). Due to its high affinity to bind fibrinogen, the release of high amounts of M protein during severe $S$. pyogenes infection can have grave consequences for the patient. In this regard, it was demonstrated that rapid formation of M1 protein/fibrinogen complexes in plasma-activated neutrophils resulted in high levels of plasma leakage, which is one of the events involved in the development of life-threatening streptococcal septic shock (Herwald et al., 2004). To clarify the molecular mechanism underlying the activation of neutrophils by M1 protein/fibrinogen complexes, Macheboeuf and colleagues determined the resolution crystal structure of an M1 protein/fibrinogen complex (Macheboeuf et al., 2011). They found that a conformationally dynamic coiled-coil dimer of M1 organized four fibrinogen molecules into a specific cross-like pattern that supported the construction of a supramolecular network (Macheboeuf et al., 2011). This supramolecular structure presented high densities of integrin-binding sites required for neutrophil activation (Macheboeuf et al., 2011). The M1 protein/fibrinogen supramolecular networks contributed to pathogenesis since blocking M1-fibrinogen interactions was shown to reduce $S$. pyogenes virulence both in vitro and in vivo (Uchiyama et al., 2013). Fibrinogen binding to surface-exposed M protein was also reported to confer bacterial resistance to phagocytosis by inhibiting complement deposition via the classical pathway (Carlsson et al., 2005). However, the functional effect of $M$ protein-fibrinogen interactions differs depending on the $M$ protein type. Thus, whereas binding of fibrinogen by the M5 protein inhibited complement activation (Carlsson et al., 2005), the binding of fibrinogen to M6 protein had not effect on complement deposition or resistance to phagocytosis (Horstmann et al., 1992). The reasons for these differences remain a matter of debate.

Fibrinogen has been also reported to serve as a docking molecule that attaches $S$. pyogenes to the pro-coagulant microvesicles described in a previous section (Oehmcke et al., 2013). This interaction leads to an alteration of the bacterial surface into a 
pro-coagulative state and immobilization of $S$. pyogenes within a clot (Oehmcke et al., 2013). The clots generated in the presence of pro-coagulant microvesicles have antimicrobial activity against $S$. pyogenes, which could be mediated by the antimicrobial peptides and other immune response proteins present in the microvesicles (Oehmcke et al., 2013). Local treatment of S. pyogenes-infected mice with pro-coagulant microvesicles results in reduced bacterial spreading and improved survival of infected animals indicating that interaction of $S$. pyogenes with pro-coagulant microvesicles may be an integral part of the innate immune response to this pathogen (Oehmcke et al., 2013). Oehmcke and colleagues also reported that fibrinogen in complex with M1 protein can trigger polymorphonuclear neutrophils to release extracellular traps (NETs) (Oehmcke et al., 2009b), which are made of processed chromatin bound to granular and selected cytoplasmic proteins (Brinkmann et al., 2004). Therefore, they proposed that the recruitment and activation of the contact system by NETs amplifies the innate immune response during streptococcal infection (Oehmcke et al., 2013).

\section{EXPLOITATION OF HOST FIBRINOLYTIC SYSTEM BY S. PYOGENES}

Fibrinolysis is the physiological process by which insoluble fibrin clots are removed through enzymatic digestion of the cross-linked fibrin polymers (Cesarman-Maus and Hajjar, 2005). Under physiological conditions, both coagulation and fibrinolysis are strictly regulated to assure blood fluidity while preventing blood loss (Kolev and Machovich, 2003). Plasmin is the major fibrinolytic protease responsible for the lysis of fibrin to produce smaller fragments resulting in the degradation of fibrin clots. Furthermore, plasmin is capable of degrading extracellular matrix proteins and activates matrix metalloproteinases leading to tissue damage (Plow et al., 1995; Monea et al., 2002). Plasmin is generated from circulating plasma plasminogen by both tissue plasminogen activator (tPA) as well as by urokinase (uPA) (Figure 1). These activators are present at various anatomical sites such as the vascular endothelium.

As described above, activation of the coagulation system upon infection can lead to entrapment of $S$. pyogenes within the fibrin network, thus preventing bacterial spreading. To counteract this entrapment, $S$. pyogenes has evolved strategies to induce fibrinolysis and to escape from the clot as depictured in Figure 4. The fibrinolytic activity of $S$. pyogenes was described already in 1933 (Tillett and Garner, 1933). Garner and Tillett identified the streptococcal factor responsible for the fibrinolytic activity that they designated as Fibrinolysin (Garner and Tillett, 1934) and later was renamed Streptokinase (SK) (Green, 1948). SK produced by $S$. pyogenes is highly specific for human plasminogen (Marcum and Kline, 1983). To overcome this limitation and evaluated the role of SK in experimental murine infection models, Khil et al. (2003) co-administered exogenous human plasminogen together with $S$. pyogenes into mice. They reported enhanced skin lesions areas and greater mortality in mice inoculated with wild-type $S$. pyogenes co-administered with human plasminogen that in mice inoculated with SK-deficient S. pyogenes also in the presence of human plasminogen (Khil et al.,

\section{Coagulation}

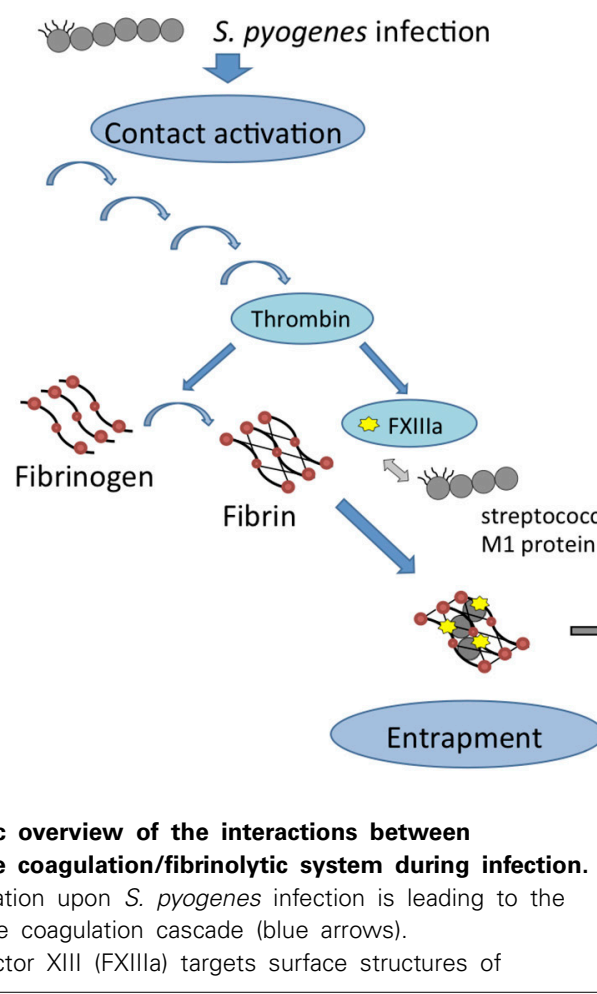

Fibrinolysis
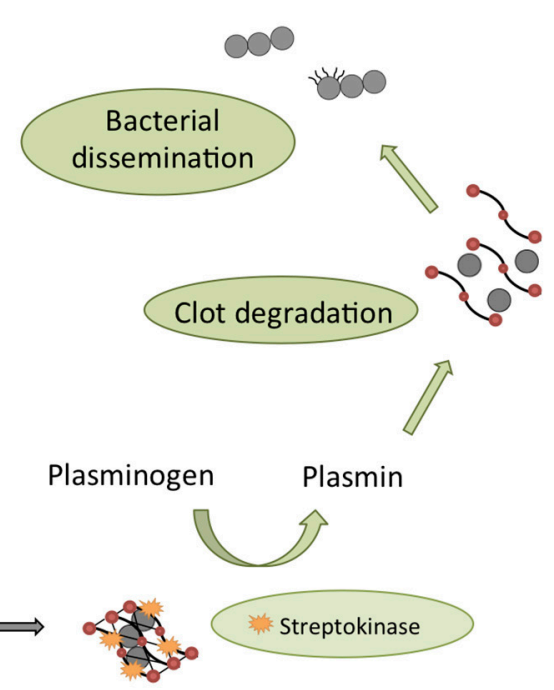

S. pyogenes such as the M1 protein and leads to bacterial entrapment within the fibrin network of the clot. S. pyogenes can counteract this mechanism by inducing fibrinolysis (green arrows) through the secretion of Streptokinase. Fibrinolysis is leading to clot degradation and therefore enables the dissemination of $S$. pyogenes. 
2003). Similarly, enhanced virulence of $S$. pyogenes was observed by Li et al. (1999) after pre-incubating streptococci in human plasma but not in plasminogen-depleted plasma. The important role of plasminogen in the pathogenesis of $S$. pyogenes infection was further demonstrated using "humanized" transgenic mice expressing human plasminogen (Sun et al., 2004). The transgenic mice expressing human plasminogen exhibited greater susceptible to subcutaneously inoculated $S$. pyogenes than mice expressing the native murine plasminogen (Sun et al., 2004). Furthermore, the increased susceptibility of human plasminogen transgenic mice to $S$. pyogenes was largely abrogated after deletion of SK (Sun et al., 2004). Thus, the SK-plasminogen interaction was demonstrated to be an important determinant of $S$. pyogenes invasiveness in vivo. These authors (Sun et al., 2004) also examined the impact on bacterial pathogenicity of recruiting plasminogen by protein PAM, which is expressed by a subset of $S$. pyogenes strains associated with skin infections (Bessen et al., 1996). PAM-expressing streptococci acquired surface-bound plasmin that contributed to bacterial virulence (Ringdahl et al., 1998). Human plasminogen transgenic mice were much more susceptible to PAM-expressing S. pyogenes than to an isogenic derivative deficient in the expression of PAM, even in the presence of SK (Sun et al., 2004). Therefore, the ability to recruit plasminogen at the bacterial surface provides and additional mechanism of $S$. pyogenes to promote pericellular fibrinolysis and degradation of components of extracellular matrix and subsequent tissue invasion. Based on these observations, pharmacological disruption of SK activity has been proposed as potential therapeutic strategy to treat severe invasive S. pyogenes infections (McArthur et al., 2012). In this regard, a compound designated as CCG-2979, was identified as capable to inhibit gene expression of SK through a highthroughput, growth-based screen on a library of 55,000 small molecules (Sun et al., 2012). Treatment with CCG-2979 enhanced both granulocyte phagocytosis and killing of $S$. pyogenes in vitro and protected mice from S. pyogenes-induced mortality (Sun et al., 2012). A series of novel compounds analogs to CCG-2979 has been constructed by Yestrepsky et al. (2013) with improved physico-chemical properties and potent Staphylococcus aureus biofilm inhibitory effect. The anti-infective efficacy of these new compounds during in vivo infection remains to be determined.

Surface-acquired plasmin activity by $S$. pyogenes has also been shown to degrade host cathelicidin antimicrobial peptides (Hollands et al., 2012). Cathelicidin peptides are important for host defense against S. pyogenes (Nizet et al., 2001). Therefore, the co-optation of the host protease activity represents an additional mechanism of $S$. pyogenes to resist the antimicrobial effect of cathelicidins.

\section{CONCLUDING REMARKS}

The experimental evidence discussed in this review clearly demonstrates a bi-directional relationship between the coagulation/fibrinolytic system and $S$. pyogenes. A schematic overview of these interactions is depictured in Figure 4. Coagulation is important in host responses to $S$. pyogenes and the activation of the contact system and local formation of fibrin prevents spread of the invading pathogen. However, S. pyogenes is also capable to hijack the fibrinolytic system to evade this host response.
S. pyogenes exploits the host fibrinolysis not only for dismantling the imprisoning fibrin clot but also for degrading the extracellular matrix and invade the surrounding tissue. Hence, the balance between the antimicrobial effect of the coagulation system and the bacterial exploitation of the host fibrinolysis is a critical point that will determine the progression of $S$. pyogenes infection. Therefore, pharmacological intervention that will balance coagulation and fibrinolysis may be of benefit for the treatment of severe $S$. pyogenes infection.

\section{ACKNOWLEDGMENTS}

The authors would like to thank Dr. Matthias Mörgelin (Department of Clinical Sciences, Lund University, Lund, Sweden) for kindly providing the scanning electron micrographs.

\section{REFERENCES}

Ben Nasr, A. B., Herwald, H., Müller-Esterl, W., and Björck, L. (1995). Human kininogens interact with $M$ protein, a bacterial surface protein and virulence determinant. Biochem. J. 305, 173-180.

Ben Nasr, A., Herwald, H., Sjobring, U., Renné, T., Muller-Esterl, W., and Björck, L. (1997). Absorption of kininogen from human plasma by Streptococcus pyogenes is followed by the release of bradykinin. Biochem. J. 326, 657-660.

Ben Nasr, A., Olsen, A., Sjobring, U., Muller-Esterl, W., and Björck, L. (1996). Assembly of human contact phase proteins and release of bradykinin at the surface of curli-expressing Escherichia coli. Mol. Microbiol. 20, 927-935. doi: 10.1111/j.1365-2958.1996.tb02534.x

Berge, A., and Björck, L. (1995). Streptococcal cysteine proteinase releases biologically active fragments of streptococcal surface proteins. J. Biol. Chem. 270, 9862-9867. doi: 10.1074/jbc.270.17.9862

Bessen, D., Sotir, C. M., Readdy, T. M., and Hollingshead, S. K. (1996). Genetic correlates of throat and skin isolates of group A streptococci. J. Infect. Dis. 173, 896-900. doi: 10.1093/infdis/173.4.896

Blombäck, B., Hessel, B., Hogg, D., and Therkildsen, L. (1978). A two-step fibrinogen-fibrin transition in blood coagulation. Nature 275, 501-505. doi: 10.1038/275501a0

Brass, L. F. (2003). Thrombin and platelet activation. Chest 124(Suppl. 3), 18S-25S. doi: 10.1378/chest.124.3_suppl.18S

Brinkmann, V., Reichard, U., Goosmann, C., Fauler, B., Uhlemann, Y., Weiss, D. S., et al. (2004). Neutrophil extracellular traps kill bacteria. Science 303, 1532-1325. doi: 10.1126/science.1092385

Brummel, K. E., Paradis, S. G., Butenas, S., and Mann, K. G. (2002). Thrombin functions during tissue factor-induced blood coagulation. Blood 100, 148-152. doi: 10.1182/blood.V100.1.148

Carlsson, F., Sandin, C., and Lindahl, G. (2005). Human fibrinogen bound to Streptococcus pyogenes $\mathrm{M}$ protein inhibits complement deposition via the classical pathway. Mol. Microbiol. 56, 28-39. doi: 10.1111/j.1365-2958.2005.04527.x

Cesarman-Maus, G., and Hajjar, K. A. (2005). Molecular mechanisms of fibrinolysis. Br. J. Haematol. 129, 307-321. doi: 10.1111/j.1365-2141.2005.05444.x

Colman, R. W., and Schmaier, A. H. (1997). Contact system: a vascular biology modulator with anticoagulant, profibrinolytic, antiadhesive, and proinflammatory attributes. Blood 90, 3819-3843.

Engelmann, B., and Massberg, S. (2013). Thrombosis as an intravascular effector of innate immunity. Nat. Rev. Immunol. 13, 34-45. doi: 10.1038/nri3345

Fischetti, V. A. (1989). Streptococcal M protein: molecular design and biological behavior. Clin. Microbiol. Rev. 2, 285-314.

Frick, I. M., Björck, L., and Herwald, H. (2007). The dual role of the contact system in bacterial infectious disease. Thromb. Haemost. 98, 497-502. doi: 10.1160/TH07-01-0051

Frick, I. M., Åkesson, P., Herwald, H., Mörgelin, M., Malmsten, M., Nägler, D. K., et al. (2006). The contact system - a novel branch of innate immunity generating antibacterial peptides. EMBO J. 25, 5569-5578. doi: 10.1038/sj.emboj.7601422

Garner, R. L., and Tillett, W. S. (1934). Biochemical studies on the fibrinolytic activity of hemolytic streptococci: I. isolation and characterization of fibrinolysin. $J$. Exp. Med. 60, 239-254. doi: 10.1084/jem.60.2.239

Green, J. (1948). Production of streptokinase and haemolysin by haemolytic streptococci. Biochem. J. 43, XXXII. 
Hasan, A. A., Cines, D. B., Herwald, H., Schmaier, A. H., and Müller-Esterl, W. (1995). Mapping the cell-binding site on high molecular weight kininogen domain 5. J. Biol. Chem. 270, 19256-19261. doi: 10.1074/jbc.270.33.19256

Henningham, A., Barnett, T. C., Maamary, P. G., and Walker, M. J. (2012). Pathogenesis of group A streptococcal infections. Discov. Med. 13, 329-342.

Herwald, H., Collin, M., Müller-Esterl, W., and Björck, L. (1996). Streptococcal cysteine proteinase releases kinins: a virulence mechanism. J. Exp. Med. 184, 665-673. doi: 10.1084/jem.184.2.665

Herwald, H., Cramer, H., Mörgelin, M., Russell, W., Sollenberg, U., NorrbyTeglund, A., et al. (2004). M protein, a classical bacterial virulence determinant, forms complexes with fibrinogen that induce vascular leakage. Cell 116 367-379. doi: 10.1016/S0092-8674(04)00057-1

Herwald, H., Mörgelin, M., Olsén, A., Rhen, M., Dahlbäck, D., Müller-Esterl, W., et al. (1998). Activation of the contact-phase system on bacterial surfaces: a clue to serious complications in infectious diseases. Nat. Med. 4, 298-302. doi: 10.1038/nm0398-298

Hollands, A., Gonzalez, D., Leire, E., Donald, C., Gallo, R. L., Sanderson-Smith, M., et al. (2012). A bacterial pathogen co-opts host plasmin to resist killing by cathelicidin antimicrobial peptides. J. Biol. Chem. 287, 40891-40897. doi: 10.1074/jbc.M112.404582

Holm, K., Frick, I. M., Bjorck, L., and Rasmussen, M. (2011). Activation of the contact system at the surface of Fusobacterium necrophorum represents a possible virulence mechanism in Lemierre's syndrome. Infect. Immun. 79, 3284-3290. doi: 10.1128/IAI.05264-11

Horstmann, R. D., Sievertsen, H. J., Leippe, M., and Fischetti, V. A. (1992). Role of fibrinogen in complement inhibition by streptococcal M protein. Infect. Immun. 60, 5036-5041.

Kantor, F. S. (1965). Fibrinogen precipitation by streptococcal M protein. I. identity of the reactants, and stoichiometry of the reaction. J. Exp. Med. 121, 849-859. doi: 10.1084/jem.121.5.849

Kantor, F. S., and Cole, R. M. (1959). A fibrinogen precipitating factor (FPF) of group A streptococci. Proc. Soc. Exp. Biol. Med. 102, 146-150. doi 10.3181/00379727-102-25172

Khil, J., Im, M., Heath, A., Ringdahl, U., Mundada, L., Cary-Engleberg, N., et al. (2003). Plasminogen enhances virulence of group A streptococci by streptokinase-dependent and streptokinase-independent mechanisms. J. Infect. Dis. 188, 497-505. doi: 10.1086/377100

Kolev, K., and Machovich, R. (2003). Molecular and cellular modulation of fibrinolysis. Thromb. Haemost. 89, 610-621.

Krem, M. M., and Di Cera, E. (2002). Evolution of enzyme cascades from embryonic development to blood coagulation. Trends Biochem. Sci. 27, 67-74. doi: 10.1016/S0968-0004(01)02007-2

Li, Z., Ploplis, V. A., French, E. L., and Boyle, M. D. (1999). Interaction between group A streptococci and the plasmin(ogen) system promotes virulence in a mouse skin infection model. J. Infect. Dis. 179, 907-914. doi: 10.1086/314654

Loof, T. G., Mörgelin, M., Johansson, L., Oehmcke, S., Olin, A. I., Dickneite, G., et al. (2011b). Coagulation, an ancestral serine protease cascade, exerts a novel function in early immune defense. Blood 118, 2589-2598. doi: 10.1182/blood2011-02-337568

Loof, T. G., Schmidt, O., Herwald, H., and Theopold, U. (2011a). Coagulation systems of invertebrates and vertebrates and their roles in innate immunity: the same side of two coins? J. Innate Immun. 3, 34-40. doi: 10.1159/0003 21641

Maas, C., Oschatz, C., and Renné, T. (2011). The plasma contact system 2.0. Semin. Thromb. Hemost. 37, 375-381. doi: 10.1055/s-0031-1276586

Macheboeuf, P., Buffalo, C., Zinkernagel, A. S., Cole, J. N., Johnson, J. E., Nizet, V., et al. (2011). Streptococcal M1 proteins constructs a pathologic host fibrinogen network. Nature 472, 64-68. doi: 10.1038/nature09967

Marcum, J. A., and Kline, D. L. (1983). Species specificity of streptokinase. Comp. Biochem. Physiol. B 75, 389-394. doi: 10.1016/0305-0491(83)90345-0

Matsuda, Y., Osaki, T., Hashii, T., Koshiba, T., and Kawabata, S. (2007). A cysteine-rich protein from an arthropod stabilizes clotting mesh and immobilizes bacteria at injury sites. J. Biol. Chem. 282, 33545-33552. doi: 10.1074/jbc.M705854200

McArthur, J. D., Cook, S. M., Venturini, C., and Walker, M. J. (2012). The role of streptokinase as a virulence determinant of Streptococcus pyogenes potential for therapeutic targeting. Curr. Drug Targets 13, 297-307. doi: $10.2174 / 138945012799424589$
Monea, S., Lehti, K., Keski-Oja, J., and Mignatti, P. (2002). Plasmin activates promatrix metalloproteinase- 2 with a membrane-type 1 matrix metalloproteinasedependent mechanism. J. Cell. Physiol. 192, 160-170. doi: 10.1002/jcp.10126

Murphy, E. C., Mörgelin, M., Cooney, J. C., and Frick, I. M. (2011). Interaction of Bacteroides fragilis and Bacteroides thetaiotaomicron with the kallikrein-kinin system. Microbiology 157(Pt. 7), 2094-2105. doi: 10.1099/mic.0.046862-0

Nickel, K. F., and Renné, T. (2012). Crosstalk of the plasma contact system with bacteria. Thromb. Res. 130(Suppl. 1), S78-S83. doi: 10.1016/j.thromres.2012.08.284

Nizet, V., Ohtake, T., Lauth, X., Trowbridge, J., Rudisill, J., Dorschner, R. A., et al. (2001). Innate antimicrobial peptide protects the skin from invasive bacterial infection. Nature 414, 454-457. doi: 10.1038/35106587

Nordahl, E. A., Rydengård, V., Mörgelin, M., and Schmidtchen, A. (2005). Domain 5 of high molecular weight kininogen is antibacterial. J. Biol. Chem. 280, 34832-34839. doi: 10.1074/jbc.M507249200

Oehmcke, S., Mörgelin, M., and Herwald, H. (2009b). Activation of the human contact system on neutrophil extracellular traps. J. Innate Immun. 1, 225-230. doi: $10.1159 / 000203700$

Oehmcke, S., Mörgelin, M., Malmström, J., Linder, A., Chew, M., Thorlacius, H., et al. (2012). Stimulation of blood mononuclear cells with bacterial virulence factors leads to the release of pro-coagulant and pro-inflammatory microparticles. Cell. Microbiol. 14, 107-119. doi: 10.1111/j.1462-5822.2011.01705.x

Oehmcke, S., Shannon, O., Mörgelin, M., and Herwald, H. (2010). Streptococcal $\mathrm{M}$ proteins and their role as virulence determinants. Clin. Chim. Acta 411, 1172-1180. doi: 10.1016/j.cca.2010.04.032

Oehmcke, S., Shannon, O., von Köckritz-Blickwede, M., Mörgelin, M., Linder, A., Olin, A. I., et al. (2009a). Treatment of invasive streptococcal infection with a peptide derived from human high-molecular weight kininogen. Blood 114, 444-451. doi: 10.1182/blood-2008-10-182527

Oehmcke, S., Westman, J., Malmström, J., Mörgelin, M., Olin, A. I., Kreikemeyer, B., et al. (2013). A novel role for pro-coagulant microvesicles in the early host defense against Streptococcus pyognes. PLoS Pathog. 9:e1003529. doi: 10.1371/journal.ppat.1003529

Ooe, K., Nakada, H., Udagawa, H., and Shimizu, Y. (1999). Severe pulmonary hemorrhage in patients with serious group A streptococcal infections: report of two cases. Clin. Infect. Dis. 28, 1317-1319. doi: 10.1086/514785

Påhlman, L. I., Mörgelin, M., Kasetty, P., Olin, A. I., Schmidtchen, A., and Herwald, H. (2013). Antimicrobial activity of fibrinogen and fibrinogen-derived peptides - a novel link between coagulation and innate immunity. Thromb. Haemost. 109, 930-939. doi: 10.1160/TH12-10-0739

Piccin, A., Murphy, W. G., and Smith, O. P. (2007). Circulating microparticles: pathophysiology and clinical implications. Blood Rev. 21, 157-171. doi: 10.1016/j.blre.2006.09.001

Plow, E. F., Herren, T., Redlitz, A., Miles, L. A., and Hoover-Plow, J. L. (1995). The cell biology of the Plasminogen system. FASEB J. 9, 939-945.

Rapala-Kozik, M., Bras, G., Chruscicka, B., Karkowska-Kuleta, J., Sroka, A., Herwald, H., et al. (2011). Adsorption of components of the plasma kininforming system on the surface of Porphyromonas gingivalis involves gingipains as the major docking platforms. Infect. Immun. 79, 797-805. doi: 10.1128/IAI.00966-10

Renné, T. (2012). The procoagulant and proinflammatory plasma contact system. Semin. Immunopathol. 34, 31-41. doi: 10.1007/s00281-011-0288-2

Renné, T., Pozgajova, M., Gruner, S., Schuh, K., Pauer, H. U., Burfeind, P., et al. (2005). Defective thrombus formation in mice lacking coagulation factor XII. J. Exp. Med. 202, 271-281. doi: 10.1084/jem.20050664

Renné, T., Schmaier, A. H., Nickel, K. F., Blombäck, M., and Maas, C. (2012). In vivo roles of factor XII. Blood. 120, 4296-4303. doi: 10.1182/blood-2012-07292094

Ringdahl, U., Svensson, M., Wistedt, A. C., Renné, T., Kellner, R., Müller-Esterl, W., et al. (1998). Molecular co-operation between protein PAM and streptokinase for plasmin acquisition by Streptococcus pyogenes. J. Biol. Chem. 273, 6424-6430. doi: 10.1074/jbc.273.11.6424

Rotstein, O. D. (1992). Role of fibrin deposition in the pathogenesis of intraabdominal infection. Eur. J. Clin. Microbiol. Infect. Dis. 11, 1064-1068. doi: 10.1007/BF01967800

Shannon, O., Rydengård, V., Schmidtchen, A., Mörgelin, M., Alm, P., Sørensen, O. E., et al. (2010). Histidin-rich glycoprotein promotes bacterial entrapment in clots and decreases mortality in a mouse model of sepsis. Blood 116, 2365-2372. doi: 10.1182/blood-2010-02-271858 
Smith-Erichsen, N., Aasen, A. O., Gallimore, M. J., and Amundsen, E. (1982). Studies of components of the coagulation systems in normal individuals and septic shock patients. Circ. Shock 9, 491-497.

Sriskandan, S., Kemball-Cook, G., Moyes, D., Canvin, J., Tuddenham, E., and Cohen, J. (2000). Contact activation in shock caused by invasive group A Streptococcus pyogenes. Crit. Care Med. 28, 3684-3691. doi: 10.1097/00003246200011000-00025

Sun, H., Ringdahl, U., Homeister, J. W., Fay, W. P., Engleberg, N. C., Yang, A. Y., et al. (2004). Plasminogen is a critical host pathogenicity factor for group A streptococcal infection. Science 305, 1283-1286. doi: 10.1126/science.1101245

Sun, H., Wang, X., Degen, J. L., and Ginsburg, D. (2009). Reduced thrombin generation increases host susceptibility to group A streptococcal infection. Blood 113, 1358-1364. doi: 10.1182/blood-2008-07-170506

Sun, H., Xu, Y., Sitkiewicz, I., Ma, Y., Wang, X., Yestrepsky, B. D., et al. (2012). Inhibitor of streptokinase gene expression improves survival after group A streptococcus infection in mice. Proc. Natl. Acad. Sci. U.S.A. 109, 3469-3474. doi: 10.1073/pnas.1201031109

Tillett, W. S., and Garner, R. L. (1933). The fibrinolytic activity of hemolytic streptococci. J. Exp. Med. 58, 485-502. doi: 10.1084/jem.58.4.485

Uchiyama, S., Andreoni, F., Zürcher, C., Schilcher, K., Ender, M., Madon, J., et al. (2013). Coiled-coil irregularities of the M1 protein structure promote M1-fibrinogen interaction and influence group A Streptococcus host cell interactions and virulence. J. Mol. Med. 91, 861-869. doi: 10.1007/s00109-0131012-6

Ulett, G. C., and Adderson, E. E. (2006). Regulation of apoptosis by Grampositive bacteria. Curr. Immunol. Rev. 2, 119-141. doi: 10.2174/157339506776 843033

Vogel, R., Assfalg-Machleidt, I., Esterl, A., Machleidt, W., and Müller-Esterl, W. (1988). Proteinase-sensitive regions in the heavy chain of low molecular weight kininogen map to the inter-domain junctions. J. Biol. Chem. 263, 12661-12668.
Wang, Z., Wilhelmsson, C., Hyrsl, P., Loof, T. G., Dobes, P., Klupp, M., et al. (2010). Pathogen entrapment by Transglutaminase - a conserved early innate immune mechanism. PLoS Pathog. 6:e1000763. doi: 10.1371/journal.ppat.1000763

Yestrepsky, B. D., Xu, Y., Breen, M. E., Li, X., Rajeswaran, W. G., Ryu, J. G., et al. (2013). Novel inhibitors of bacterial virulence: development of 5,6dihydrobenzo[h]quinazolin-4 $(3 \mathrm{H})$-ones for the inhibition of group A streptococcal streptokinase expression. Bioorg. Med. Chem. 21, 1880-1897. doi: 10.1016/j.bmc.2013.01.046

Zeerleder, S., Schloesser, M., Redondo, M., Wuillemin, W. A., Engel, W., Furlan, M., et al. (1999). Re-evaluation of the incidence of thromboembolic complications in congenital factor XII deficiency - a study on 73 subjects from 14 Swiss families. Thromb. Haemost. 82, 1240-1246.

Conflict of Interest Statement: The authors declare that the research was conducted in the absence of any commercial or financial relationships that could be construed as a potential conflict of interest.

Received: 19 June 2014; paper pending published: 15 July 2014; accepted: 27 August 2014; published online: 11 September 2014.

Citation: Loof TG, Deicke C and Medina E (2014) The role of coagulation/fibrinolysis during Streptococcus pyogenes infection. Front. Cell. Infect. Microbiol. 4:128. doi: $10.3389 /$ fcimb.2014.00128

This article was submitted to the journal Frontiers in Cellular and Infection Microbiology.

Copyright (c) 2014 Loof, Deicke and Medina. This is an open-access article distributed under the terms of the Creative Commons Attribution License (CC BY). The use, distribution or reproduction in other forums is permitted, provided the original author(s) or licensor are credited and that the original publication in this journal is cited, in accordance with accepted academic practice. No use, distribution or reproduction is permitted which does not comply with these terms. 